\title{
Carrying Out Energy Audits to Determine Measures to Save Energy Resources
}

\author{
O. Vasilenko ${ }^{1}$, O. Shkrehal ${ }^{2}$, O. Kletska $^{1}$, A. Onyshchenko ${ }^{1}$, S. Voznenko ${ }^{1}$ \\ ${ }^{1}$ Ukrainian State University of Railway Transport \\ ${ }^{2}$ Kharkiv National Technical University of Agriculture named after P. Vasilenko \\ *Corresponding author E-mail: 0673966747@ukr.net
}

\begin{abstract}
It is important for a modern consumer of thermal energy to know and be able to reduce the consumption of thermal energy, for which purpose an energy audit should be conducted. Today, three types of energy audit of residential buildings are used in Ukraine. The first one is development of the energy performance certificate of the building. The obtained energy performance certificate will give an idea of the level of thermal losses of the building and identify the main areas where measures to reduce the consumption of energy resources should be taken. The second method involves carrying out experimental studies to determine the class of air permeability of enclosing structures, which also makes it possible to assess the level of heat losses of the building and the condition of the ventilation system of the building. The third type of energy audit involves carrying out thermal imaging of the building envelope for the subsequent analysis of infrared images. A methodological approach has been developed for processing multiple infrared images. An energy inspection of a residential house has been conducted on the basis of which an energy performance certificate was compiled. The premises of the residential building have been tested for air permeability. Considering the main types of energy audit, its advantages and disadvantages have been determined both for the consumer and for the employees who conduct the audit.
\end{abstract}

Keywords: air permeability, energy audit, energy performance certificate of the building, infrared images

\section{Introduction}

The current state of the economy requires decisive action in terms of saving energy resources to increase its competition in world markets. The main consumers of energy resources such as thermal energy, water and electricity are the housing and communal sector. Therefore, a decrease in consumption in the housing and communal services sector will allow solving both economic issues and reducing social tension from a sharp rise in price of resources. According to the external audit of energy efficiency [1-9], the main reasons for the low level of resource use in the housing and communal services sector in Ukraine can be identified as follows: - inefficient use of fuel;

- high level of losses in the networks during transportation of the coolant;

- heavy depreciation of fixed assets, their slow modernization; - absence of energy markets with transparent rules of regulation;

- irresponsibility of objects of state and municipal property;

- abuse of monopoly position;

- dependence on external fuel supplies;

- lack of a unified system for data collection and monitoring of energy consumption in the country;

- lack of funds, lack of mechanisms for cooperation with private investors);

- low level of consciousness and knowledge of the population;

- lack of appropriate laws, low level of implementation of laws already passed.

To resolve the above shortcomings, the Verkhovna Rada of Ukraine passed the law "Energy Efficiency of Buildings" [2] According to this law, in the near future, all buildings and facili- ties that are consumers of energy resources, an energy audit should be conducted based on the results of which owners of buildings can claim a loan from "Energy Security Fund".

The purpose of the work is to select the optimal method of energy audit, depending on the needs of the end user and in accordance with the laws in force in Ukraine. When conducting an energy audit, you need to identify both hidden energy losses and explicit ones. The ultimate purpose of the energy audit should be the development of proposals and activities for energy efficiency and control over their implementation. The object of research in the work is a residential house located in Kharkov. In the house there is a roof furnace (which includes 2 boilers of $100 \mathrm{~kW}$ each) which during the heating season provides the heating medium with a residential building. The gas corrector GAMMA-FLOU-3a installed to account for the consumption of natural gas in the gas distribution cabinet. This corrector allows keeping a real-time record of gas consumption and store the daily gas consumption in the device memory for the last 24 months. In addition, the house is equipped with a common household electricity and water meter that allows to conduct research with higher accuracy. In the considered house, complex work was carried out in 2017-2018 to conduct energy audit in various ways according to the current Ukrainian regulatory documents. Now, there are three main ways to conduct energy audits.

\section{Energy Performance Certificate of the Building}

The first method is the development of the energy performance certificate of the building in accordance with DBN [3]. The energy 
performance certificate of the building contains the energy characteristics of the building and measures for their improvement. For its development, it is necessary to obtain data from energy resource meters over the past 3-5 years, the geometric characteristics of the building and to determine what construction materials used in the construction and their current state. From the beginning of work and to the development of an energy performance certificate, the work continues for up to 3 months. The results of drawing up an energy performance certificate are shown in Table 1.

Table 1: Resulting part of the energy performance certificate of the building

\begin{tabular}{|c|c|c|c|c|}
\hline 1 & 2 & 3 & 4 & 5 \\
\hline $\begin{array}{l}\text { Maximum permissible value of } \\
\text { specific heat losses for home } \\
\text { heating }\end{array}$ & $\begin{array}{l}\mathrm{Eb} \\
\mathrm{W} \mathrm{h} / \mathrm{m}^{3}\end{array}$ & 83 & - & 83 \\
\hline \multicolumn{2}{|l|}{ Class of Energy Efficiency } & \multicolumn{3}{|l|}{$\mathrm{F}$} \\
\hline \multicolumn{2}{|c|}{$\begin{array}{l}\text { The term of effective operation of the heat- } \\
\text { insulating casing and its elements }\end{array}$} & \multicolumn{3}{|l|}{ - } \\
\hline \multicolumn{2}{|c|}{$\begin{array}{l}\text { Compliance of the project with normative } \\
\text { requirements }\end{array}$} & \multicolumn{3}{|l|}{ No } \\
\hline \multicolumn{2}{|c|}{ The need to finalize a house project } & \multicolumn{3}{|c|}{ Yes } \\
\hline \multicolumn{5}{|c|}{ Conclusions on the results of evaluation of energy parameters of the house } \\
\hline \multicolumn{5}{|c|}{ Guidelines for improving the energy efficiency of the house } \\
\hline \multicolumn{5}{|c|}{$\begin{array}{l}\text { Project for compliance with the requirements of the DBN in 2.6-31: } 2016 \\
\text { regarding the thermal engineering parameters of the enclosing structures of } \\
\text { the building. To increase the energy efficiency of a residential building, it } \\
\text { is proposed to carry out the following actions: } \\
\text { - Reconstruction and thermal insulation of the attic floor; } \\
\text { - Thermal insulation of exterior walls; } \\
\text { - Installation of regulators of heat flow to the boiler according to hourly } \\
\text { conditions; } \\
\text { - replacement of windows; } \\
\text { - Modernization of the lighting system }\end{array}$} \\
\hline
\end{tabular}

As can be seen from the presented certificate, the energy efficiency class of the building is " $F$ ", which is a low value for the building. According to regulatory documents, commissioned buildings should have a level of energy efficiency not lower than "C". Using this technique, we could identify where in the building the most significant losses of energy resources occurred, which helped develop recommendations for reducing these losses.

\section{Determination of Air Permeability of the Building}

The second method is to perform measurements to determine the air permeability of the building envelope [4]. The essence of the method consists in injecting or sucking air into the test room and after establishing a stationary airflow through the fan at a fixed pressure difference between the test room and the external environment, the airflow through the fan measured and equated to the airflow filtered through the fences, limiting the test room. Based on the measurement results, the generalized air permeability characteristics of the fences of the test room are calculated. For carrying out such measurements, special equipment such as Blower Door is needed. Such tests last from several hours to 24 hours, depending on the size of the building, and help determine the places of leakage of thermal energy and not the density of the enclosing structures. Studies carried out in two modes of air injection into the room and dilution of air. The results of the study are shown in Fig. 1.

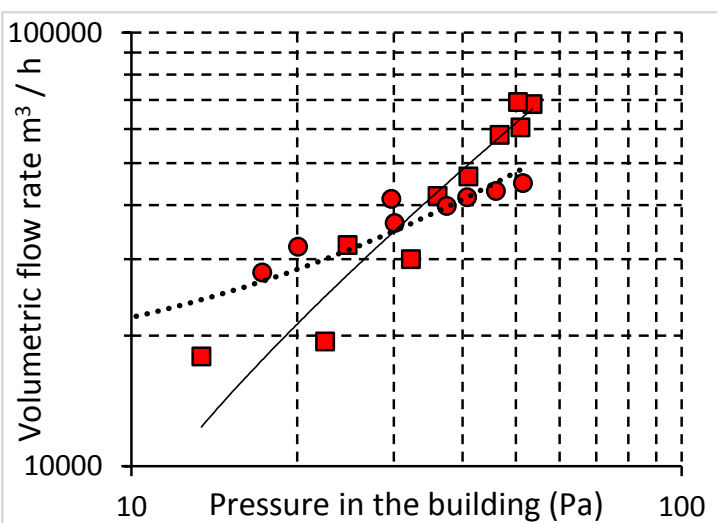

Fig. 1: Experimental characteristics of the air permeability of a building in two modes: $\square$ - air rarefaction mode; $\bigcirc$ - air injection mode

As a result of the obtained experimental characteristics, approximating dependences were obtained for the two regimes, the air injection regime:

$y=640,72 x+15624$

second mode, rarefaction mode:

$y=1353.3 x-5813.4$

where $y$ - is the air flow rate, and $x$ - is the air pressure value.

The obtained average value of the flow at negative pressure inside the building $-50 \mathrm{~Pa} \mathrm{~V}(50)=1154 \mathrm{~m}^{3} / \mathrm{h}$, allows to determine the air exchange rate, $\mathrm{n} 50=1.984 \mathrm{~h}^{-1}$, with the volume of the heated room $\mathrm{V}=481.14 \mathrm{~m}^{3}$. The obtained average value of the flow at positive pressure inside the building $50 \mathrm{~Pa} \mathrm{~V}(50)=913 \mathrm{~m}^{3} / \mathrm{h}$, allows to determine the frequency of air exchange, $\mathrm{n} 50=1.8975$ $\mathrm{h}^{-1}$, with the volume of the heated room $\mathrm{V}=481.14 \mathrm{~m}^{3}$. The average value was $n 50=2.148 \mathrm{~h}^{-1}$ and corresponds to the air permeability class $1 \leq \mathrm{n} 50<2$ "Low". This indicator indicates an inadequate system of ventilation of internal premises, which leads to additional heat losses and disturbances in the indoor climate.

\section{Thermal Imaging Study of Building Envelope}

The third method is the thermal imaging with a thermal imager. Thermal imaging of infrastructure facilities is a relatively new direction in the assessment and detection of heat losses and the detection of hidden shortcomings. Such a survey is possible with a difference in temperature inside the building and the environment from $15^{\circ} \mathrm{C}$ or more, that is, this survey is only possible in the autumn-winter period and with the heating system of the building operating. In addition, there are limitations when conducting thermography; this is the absence of direct sunlight and the absence of precipitation in the form of rain or snow. The duration of work on thermography depends on the total area of the enclosing structures, but not more than a day. In our work, we used the Flir thermal imager; this model belongs to professional thermal imagers and has a resolution of $180 \times 240$. The external conditions under which the object studied were the following. The temperature during the environmental study was $-6^{\circ} \mathrm{C}$, and the external relative humidity was $83 \%$. Studies conducted in the absence of sunlight for 12 hours before carrying out thermography. The average thermal head was $26^{\circ} \mathrm{C}$ based on the power of the heating system. Thermal control conducted in the absence of precipitation, fog at a wind speed of less than $2 \mathrm{~m} / \mathrm{s}$.

When carrying out thermography, a number of recommendations pertaining to the correct use of the instrument observed. First, the thermography carried out at a right angle to the surface of the building there were no aging objects on the surface of the building that could distort the results. The shooting conducted from the left 
to the right and from the top to the bottom. This approach allows you to remove the surface of enclosing structures of large dimensions.

Based on the recommendations that the manufacturer provides the value of the black ratio was set at 0.9 .

Based on the obtained initial data, these parameters introduced into the device and the survey performed.

To process the thermograms obtained, the method developed by the authors used. A feature of the technique is the use of the dependence (3) which allows one to obtain the average value of the blackness coefficient

$e=f(M, t, \varphi)=b_{0}+b_{1} t+b_{2} \varphi+b_{3} M$

where $M$ - is the kind of material (brick, concrete and is taken into account through the density of matter);

$t$ - is the surface temperature;

$\varphi$ - is the ratio of the areas of materials.

$b$ - free coefficients of linear approximation for the solution of the problem.

The results of thermography shown in Fig. 2

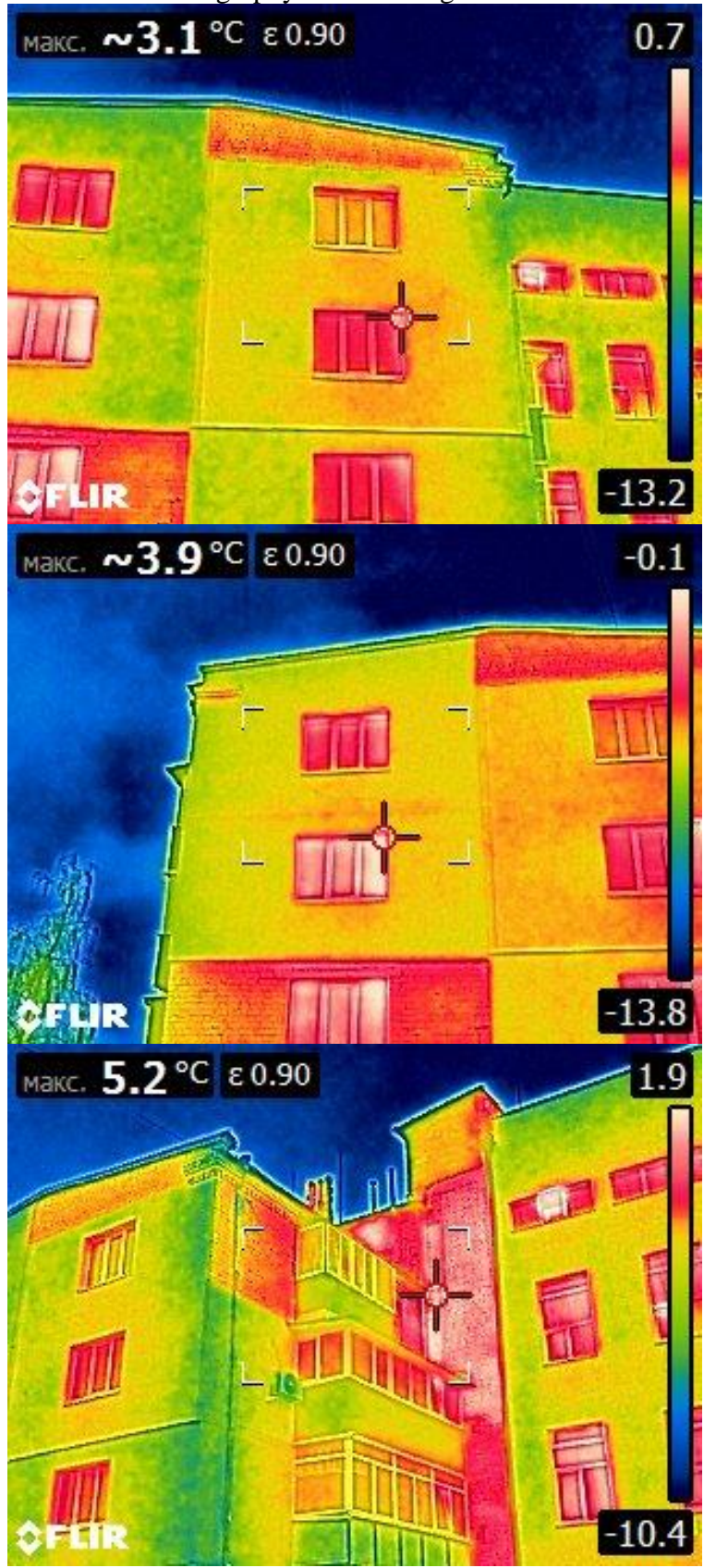

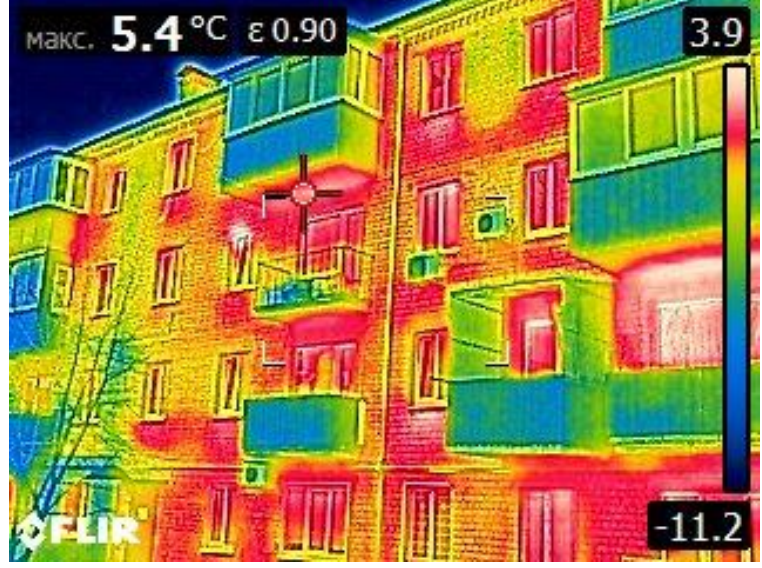

Fig. 2: Thermography of an apartment house
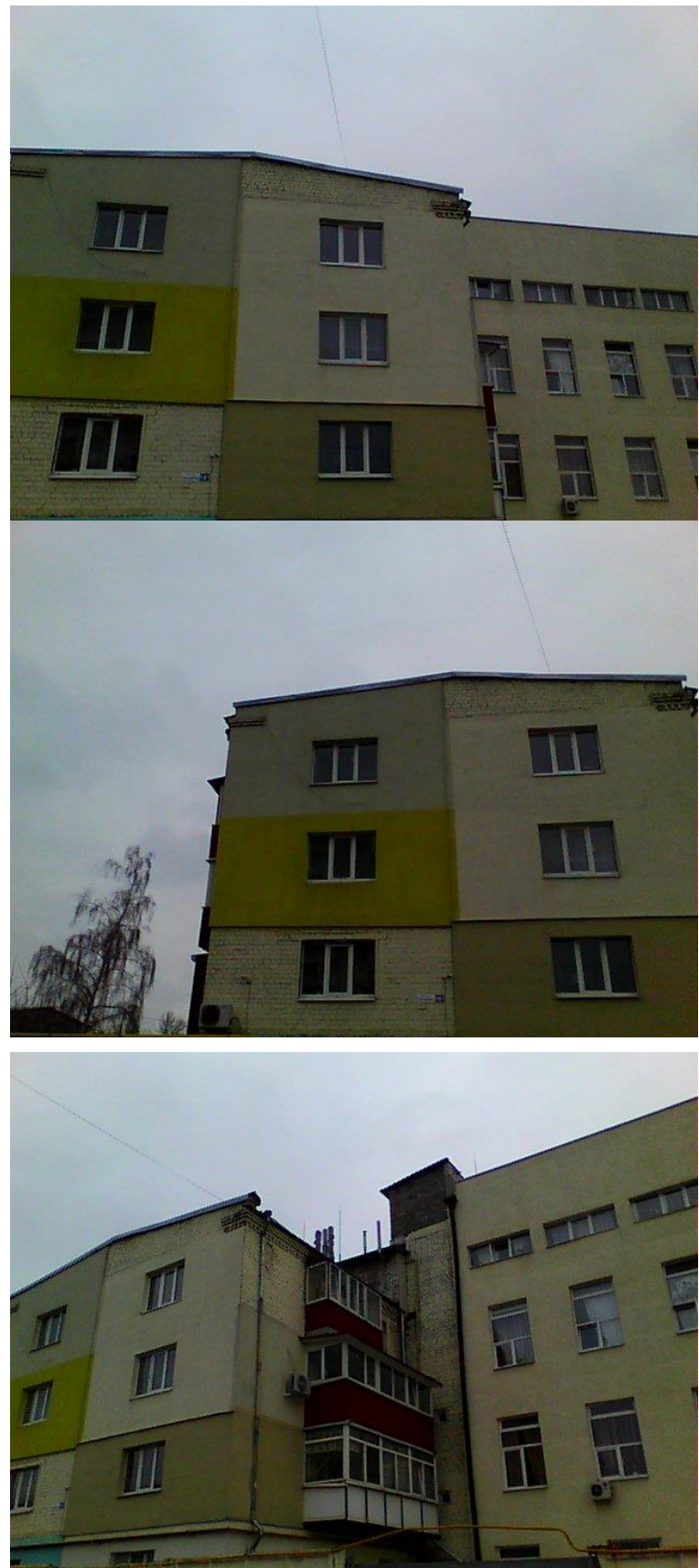


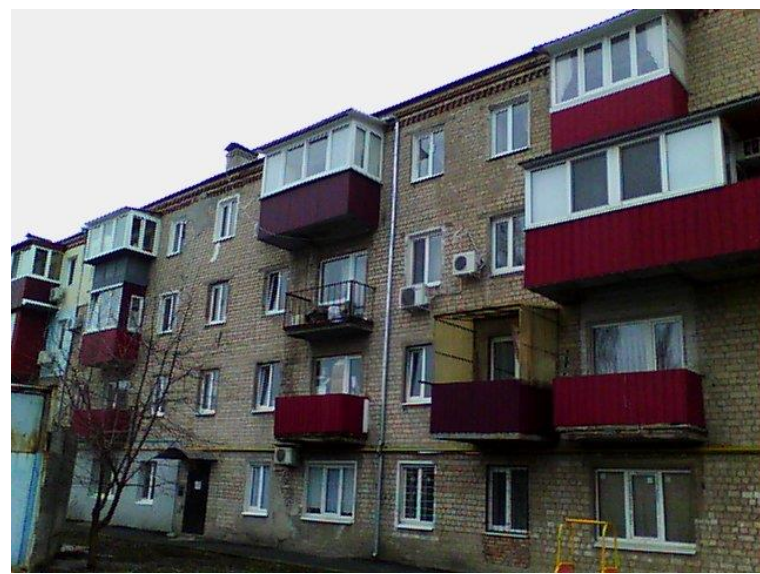

Fig. 3: Real images of an apartment house

According to the results of thermo-morphing, the main source of heat losses identified. The largest part of the heat losses is due to the translucent structures of the building, which is explained by the low value of the coefficient of thermal resistance $R=0.35$ with the minimum required 0.5 . The second part of the heat losses falls on the walls of the building. This is especially evident in the analysis of pictures where it is evident that the highest temperature on the surface falls at the places of installation of heating devices. The walls of the house on which the insulation work carried out have a lower temperature on their surface than the walls that have not been thermally insulate.

\section{Conclusion}

These methods have both advantages and disadvantages. For buildings that built and operated for a long time, it is most expedient to use the first and third method that will complement each other. For new buildings, it is necessary to use the first and second method, which allows the end user to have information on the cost of energy resources and thereby improve the efficiency of the building. If you take into account the cost of services, it should note that for the first method the cost of work specified in the law, and in the second and third costs depend on economic indicators.

\section{References}

[1] http://greenergy.com.ua/novosti/e-nergoemkost-vvp-ukrainy-v-3-4raza-vy-she-chem-v-es/

[2] ZAKON UKRAINY. Pro enerhetychnu efektyvnist budivel. Zakon ot 22.06.2017 № 2118-VIII.

[3] Teplova izoliatsiia budivel DBN V.2.6-31:2016 z 1 kvitnia 2017 r vstupaie v diiu.

[4] Nastanova $\mathrm{z}$ rozrakhunkovoi otsinky povitropronyknosti ohorodzhuvalnykh konstruktsii DSTU-N B V.2.6-191: 2013 z 1 sichnia 2014 r. vstupaie v diiu.C.A. Balaras, A.A. Argiriou, Infrared thermography for building diagnostics, Energy and Buildings, Volume 34, Issue 2, 2002.

[5] Eva Barreira, Vasco P. de Freitas, Evaluation of building materials using infrared thermography, Construction and Building Materials, Volume 21, Issue 1, 2007.

[6] Paris A. Fokaides, Soteris A. Kalogirou, Application of infrared thermography for the determination of the overall heat transfer coefficient (U-Value) in building envelopes, Applied Energy,Volume 88, Issue 12, 2011.

[7] N.P. Avdelidis, A. Moropoulou, Emissivity considerations in building thermography, Energy and Buildings, Volume 35, Issue 7, 2003

[8] D.J. Titman, Applications of thermography in non-destructive testing of structures, NDT \& E International, Volume 34, Issue 2, 2001. 